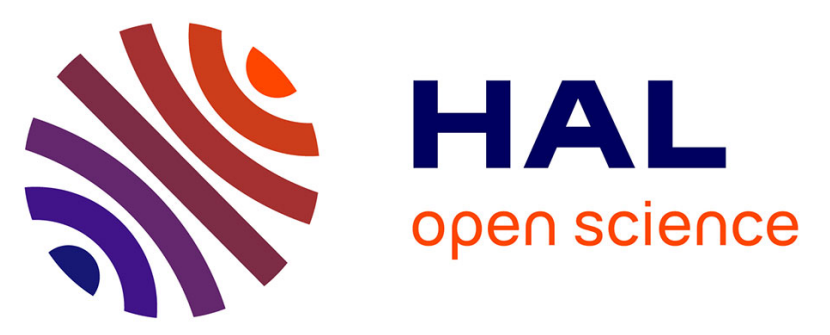

\title{
Fiber atrophy, oxidative stress, and oxidative fiber reduction are the attributes of different phenotypes in chronic obstructive pulmonary disease patients
}

Fares Gouzi, Aldjia Abdellaoui, Nicolas Molinari, Edith Pinot, Bronia Ayoub, Dalila D. Laoudj-Chenivesse, Jean-Paul Cristol, Jacques Mercier, Maurice Hayot, Christian Prefaut

\section{To cite this version:}

Fares Gouzi, Aldjia Abdellaoui, Nicolas Molinari, Edith Pinot, Bronia Ayoub, et al.. Fiber atrophy, oxidative stress, and oxidative fiber reduction are the attributes of different phenotypes in chronic obstructive pulmonary disease patients. Journal of Applied Physiology, 2013, 115 (12), pp.1796 1805. 10.1152/japplphysiol.00778.2013 . hal-01623970

\section{HAL Id: hal-01623970 \\ https://hal.umontpellier.fr/hal-01623970}

Submitted on 25 Oct 2017

HAL is a multi-disciplinary open access archive for the deposit and dissemination of scientific research documents, whether they are published or not. The documents may come from teaching and research institutions in France or abroad, or from public or private research centers.
L'archive ouverte pluridisciplinaire HAL, est destinée au dépôt et à la diffusion de documents scientifiques de niveau recherche, publiés ou non, émanant des établissements d'enseignement et de recherche français ou étrangers, des laboratoires publics ou privés. 


\title{
Fiber atrophy, oxidative stress, and oxidative fiber reduction are the attributes of different phenotypes in chronic obstructive pulmonary disease patients
}

\author{
Fares Gouzi, ${ }^{1,2}$ Aldjia Abdellaoui, ${ }^{1,3}$ Nicolas Molinari, ${ }^{4}$ Edith Pinot, ${ }^{5}$ Bronia Ayoub, ${ }^{1}$ \\ Dalila Laoudj-Chenivesse, ${ }^{1}$ Jean-Paul Cristol, ${ }^{5}$ Jacques Mercier, ${ }^{1}$ Maurice Hayot, ${ }^{1}$ and Christian Préfaut ${ }^{1}$ \\ ${ }^{1}$ INSERM U-1046, CHRU Montpellier, Department of Clinical Physiology, University of Montpellier I and II, Montpellier, \\ France; ${ }^{2}$ Pulmonary Rehabilitation Center "La Solane", Fontalvie Group, Osséja, France; ${ }^{3}$ Pulmonary Rehabilitation Center \\ "La Vallonie", Fontalvie Group, Lodève, France; ${ }^{4}$ UMR 729 MISTEA, CHRU Montpellier, Department of Medical \\ Information, University of Montpellier I, Montpellier, France; and ${ }^{5}$ UMR 204 NutriPass, Institute of Research for \\ Development, CHRU Montpellier, Department of Biochemistry, University of Montpellier I and II, Montpellier, France
}

Submitted 8 July 2013; accepted in final form 11 October 2013

Gouzi F, Abdellaoui A, Molinari N, Pinot E, Ayoub B, LaoudjChenivesse D, Cristol JP, Mercier J, Hayot M, Préfaut C. Fiber atrophy, oxidative stress, and oxidative fiber reduction are the attributes of different phenotypes in chronic obstructive pulmonary disease patients. J Appl Physiol 115: 1796-1805, 2013. First published October 17, 2013; doi:10.1152/japplphysiol.00778.2013.-Peripheral muscle dysfunction, associated with reductions in fiber cross-sectional area (CSA) and in type I fibers, is a key outcome in chronic obstructive pulmonary disease (COPD). However, COPD peripheral muscle function and structure show great heterogeneity, overlapping those in sedentary healthy subjects (SHS). While discrepancies in the link between muscle structure and phenotype remain unexplained, we tested whether the fiber CSA and the type I fiber reductions were the attributes of different phenotypes of the disease, using unsupervised clustering method and post hoc validation. Principal component analysis performed on functional and histomorphological parameters in 64 COPD patients fforced expiratory volume in $1 \mathrm{~s}\left(\mathrm{FEV}_{1}\right)=42.0$ $[30.0-58.5] \%$ predicted $\}$ and 27 SHS $\left(\mathrm{FEV}_{1}=105.0[95.0-114.0] \%\right.$ predicted) revealed two COPD clusters with distinct peripheral muscle dysfunctions. These two clusters had different type I fiber proportion $(26.0 \pm 14.0 \%$ vs. $39.8 \pm 12.6 \% ; P<0.05)$, and fiber CSA $\left(3,731 \pm 1,233\right.$ vs. $\left.5,657 \pm 1,098 \mu \mathrm{m}^{2} ; P<0.05\right)$. The "atrophic" cluster showed an increase in muscle protein carbonylation (131.5 [83.6-200.3] vs. 83.0 [68.3-105.1]; $P<0.05$ ). Then, COPD patients underwent pulmonary rehabilitation. If the higher risk of exacerbations in the "atrophic" cluster did not reach statistical significance after adjustment for $\mathrm{FEV}_{1}$ (hazard ratio: $2.43 ; P=0.11, n=54$ ), the improvement of $\mathrm{VO}_{2} \mathrm{sl}$ after training was greater than in the nonatrophic cluster $(+24 \pm 16 \%$ vs. $+6 \pm 13 \% ; P<0.01)$. Last, their age was similar ( $60.4 \pm 8.8$ vs. $60.8 \pm 9.0 \mathrm{yr} ; P=0.87)$, suggesting a different time course of the disease. We identified and validated two phenotypes of COPD patients showing different muscle histomorphology and level of oxidative stress. Thus our study demonstrates that the muscle heterogeneity is the translation of different phenotypes of the disease.

atrophy; muscle dysfunction; physical activity; oxidative stress; cluster analysis

CHRONIC OBSTRUCTIVE PULMONARY DISEASE (COPD) is a composite disease with significant extrapulmonary effects that may contribute to the degree of severity in individual patients. Peripheral muscle dysfunction is one of these effects and constitutes a key outcome $(7,14)$, as reduced quadriceps

Address for reprint requests and other correspondence: F. Gouzi, INSERM U-1046, Univ. Montpellier I, Univ. Montpellier II, Dept. of Clinical Physiology, CHRU Montpellier, 34295 Montpellier Cedex 5, France (e-mail: f-gouzi @ chu-montpellier.fr). muscle strength and mass have been linked to the patient prognosis $(33,51)$. The reduction in muscle mass is closely related to the reduction in fiber cross-sectional area (CSA) (19). In addition, a loss in muscle oxidative capacity, which is characterized by a reduction in type I fiber proportion, is another well-documented feature of COPD peripheral muscle $(20,53)$ directly impacting patient endurance (53).

Yet, the picture is complexified by the great heterogeneity of the muscle structure in COPD, with patients showing a wide variability in both fiber CSA and type I fiber proportion (20). Studies have suggested that the reduction in the fiber CSA and in the type I fiber proportion were not related $(34,53)$. Moreover, while a significant proportion of COPD patients shows normal muscle structure (20), small fiber size and type I fiber regression can even be observed in healthy subjects (47) [older and sedentary subjects, in particular (21)]. This heterogeneity in peripheral muscle dysfunction and structure has limited research studies, as well as clinical care. Indeed, the variability in parameter values has made it difficult to identify the cellular mechanisms of fiber atrophy and type I fiber regression in COPD patients. In particular, it is unknown whether muscle oxidative stress, which has been incriminated in the muscle weakness (6) and impaired endurance (30), is specifically associated with the muscle fiber atrophy in COPD patients $(17,45)$. Second, patients with fiber atrophy, who present a worse prognosis, may be more responsive to specific therapeutics like muscle electromyostimulation (3). However, these patients remain generally unrecognized in routine care.

Using unsupervised clustering methods, recent studies have demonstrated that the clinical heterogeneity in COPD is the consequence of the different phenotypes of the disease $(9,10$, 18). Phenotypes are homogeneous patient subgroups within the wide spectrum of COPD, with "unique prognostic or therapeutic characteristics" (24).

Previous studies in COPD have isolated a cluster characterized by the specific occurrence of a weight and fat-free mass loss and/or muscle weakness, indicating a muscle atrophy ( 9 , $10,16,51)$, and thus, a possible link between the clinical phenotype and the muscle structure (45). However, in a recent study (34), COPD patients with fiber atrophy did not show reduced muscle mass and strength, but a better exercise capacity, as compared to COPD patient without fiber atrophy. These discrepancies with other studies $(9,10,18)$ could be explained by the use of a supervised clustering approach, leading to misclassification of subjects. In addition, the clusters isolated cannot be considered as a "phenotype" because not prospec- 
tively validated (24). Therefore, the aim of this study was to test the hypothesis that- using unsupervised clustering methods - the muscle fiber atrophy and increased oxidative stress constitute the attributes of validated COPD phenotypes that differs from phenotypes characterized by the reduction of type I fibers. Because of the redundancy in the multidimensional datasets obtained in COPD patients and healthy subjects of the same age and physical activity level, cluster analysis was performed on both populations.

\section{MATERIALS AND METHODS}

Study population. Sedentary healthy subjects (SHS) were recruited on the basis of the following criteria: age from 50 to $75 \mathrm{yr}$, no disease, and less than $150 \mathrm{~min}$ of moderate-to-vigorous physical activity per week (35). COPD patients were defined on the basis of the following criteria: dyspnea, chronic cough or sputum production, and/or a history of exposure to risk factors for the disease, and diagnosis confirmed by spirometry [postbronchodilatator forced expiratory volume in $1 \mathrm{~s} /$ forced vital capacity $\left(\mathrm{FEV}_{1} / \mathrm{FVC}\right)<70 \%$ ] (43). Exclusion criteria were other respiratory diagnosis, decompensated comorbidity, and exacerbation in the last 2 mo. The severity of breathlessness was assessed via the Medical Research Council (MRC) scale (8). All subjects and patients performed the tests at INSERM U-1046, CHRU Montpellier, France, or at the "La Solane" and "La Vallonie" Pulmonary Rehabilitation Centers in Osseja and Lodève, France, respectively. An informed written consent was obtained from all subjects, and the research protocol was approved by the institutional ethics committee of the Montpellier University Hospitals (no. 2008-03ESSS-V2 and no. 2009-04-BPCO-V2) and conducted in accordance with the Helsinki Declaration and the European Guidelines for "good clinical practice."

Physical activity. In order to assess the physical activity (PA) level of our sedentary-selected healthy population, we used the Voorrips questionnaire (modified Baecke's questionnaire) validated and used in this indication $(22,56)$. "Objective" PA level was assessed in 25 COPD patients and 22 SHS who wore a triaxial accelerometer for 7 consecutive days (Tritrac RT3 Research, Stayhealthy, Monrovia, CA). This triaxial accelerometer is worn at the waist and records the acceleration in the three axis of the space $(x, y, z)$, every minute. The parameter analysis is the Vector Magnitude Unit (VMU) or activity counts: $\mathrm{VMU}=\sqrt{ }\left(x^{2}+y^{2}+z^{2}\right)$ and has been validated in COPD (50).

The QUANTAP interview-administered survey is a computerassisted tool designed to determine PA over a lifetime in four dimensions (sports at school, leisure sports, occupation, daily activities). This questionnaire is reliable to assess lifetime PA and has been validated for use in elderly French subjects and in the context of COPD (23).

Pulmonary function tests and arterial blood gases. All subjects underwent whole body plethysmography (Transmural Bodybox 2800; Sensomedics, Yorba Linda, CA). FEV ${ }_{1}, \mathrm{FVC}$, functional residual capacity (FRC), total lung capacity (TLC), and residual volume (RV) were measured. The $\mathrm{FEV}_{1} / \mathrm{FVC}, \mathrm{RV} / \mathrm{TLC}$ and $\mathrm{FRC} / \mathrm{TLC}$ ratios were calculated. The values were compared with normal values (44). Arterial blood samples were obtained while breathing room air. $\mathrm{Pa}_{2}$ was measured with a blood gas analyzer (Roche OMNI S, Roche Diagnostics, Mannheim, Germany).

Exercise capacity. The 6-min walking test (6MWT), which is routinely used by our group (39), was performed in a 30-m corridor. The distance walked during the test (6MWD) was compared with reference values (1). Arterial oxygen saturation $(\mathrm{SpO} 2)$ and heart rate (HR) were monitored using a pulse oximeter (Nonin $8500 \mathrm{M}$; Nonin Medical, Minneapolis, MN).

Participants performed an incremental cycle ergometric test until exhaustion on an electrically braked cycle ergometer (Ergoselect
200P, Ergolyne, Bitz, Germany) following the individualized protocol usually used in our laboratory (46), and according to the international standards (2). Oxygen consumption $\left(\mathrm{VO}_{2}\right)$ and carbon dioxide production $\left(\mathrm{VCO}_{2}\right)$ were measured and calculated from breath-by-breath analysis (Sensormedics, Vmax 229, Autobox, Yorba Linda, CA). Maximal power output was the maximal workload sustainable, and symptom-limited $\left(\mathrm{VO}_{2} \mathrm{sl}\right)$ was the mean value during the last $20 \mathrm{~s}$ of the test. The ventilatory threshold was blindly and independently assessed for each subject by two experienced practitioners on the basis of noninvasive methods (ventilatory equivalent and V-slope methods), as recommended (2).

Muscle function assessment. The maximal voluntary contraction (MVC) and measurement to task failure time (T.lim) of the knee extensor were assessed with the usual methods of our group $(14,26$, 42). Briefly, the MVC was measured at $90^{\circ}$ on a bench (Kettler, Germany). Three reproducible measurements (within 10\%) of the force of the dominant leg were recorded and the best value was retained as the MVC. The T.lim was then measured as the time (in s) during which the subjects were able to maintain a contraction at $30 \%$ of MVC, and at the rate of 10 movements per minute to exhaustion. Because it is a volitional test, a reduction in MVC $>10 \%$ in 1 min was mandatory to validate the test. The fat-free mass index (FFMI) calculated from the fat-free mass determined with multifrequency bioelectrical impedancemetry (BIA) (QuadScan 4000, Bodystat, Isle of Man, UK) (19), using the validated equations of Kyle et al. (31).

Blood sample and muscle biopsy analysis. Venous blood was sampled in standard, sterile, heparinized tubes and muscle biopsies were performed in the vastus lateralis of the quadriceps using the usual methodology (25). Plasma-free and esterified isoprostanes (F2IsoP) were evaluated as markers of lipid (15). Muscle biopsies were performed in the vastus lateralis of the quadriceps. Muscle fiber type and CSA were assessed by immunohistochemistry on frozen sections from the muscle biopsies using a panel of antibodies (16) as previously described (3). Muscle oxidative stress markers were assessed by immunoblotting determination of protein and myosin heavy chains oxidation, lipid peroxidation, and the protein level of three enzymatic antioxidants (Mn superoxide dismutase, glutathione reductase, catalase) $(5,13,32)$, as previously described (3). Blots were scanned and the optical densities (OD) of specific proteins were quantified with ImageJ.

Pulmonary rehabilitation in COPD patients. We analyzed the response to exercise training, in terms of exercise capacity (6MWD and $\mathrm{VO}_{2} \mathrm{sl}$ ) in COPD patients only. The exercise training sessions were part of a multicomponent and comprehensive pulmonary rehabilitation course, including an education program, as recommended (36) and previously described (22). Briefly, twenty sessions of endurance exercise (stationary cycling, walking) were condensed into 4-6 wk. The training sessions were performed 3 or 4 times per week on a cycloergometer or a treadmill. The exercise intensity was set as the heart rate at the ventilatory or dyspnea threshold $(36,42,52)$ assessed during the exercise test. This intensity was continuously monitored with a cardiofrequency meter. The duration of the training session was progressively increased to $1 \mathrm{~h} 30 \mathrm{~min}$, with a maximum of $45 \mathrm{~min}$ of endurance training (10 min of work at the intensity of the ventilatory threshold followed by $5 \mathrm{~min}$ of active recovery, repeated 3 times) completed by strength-building exercise ( $8-10$ exercises, with sets of $10-15$ repetitions). The load for the resistance exercise was initially set at $40 \%$ of the isotonic one-repetition maximum (1-RM) of each muscle (deltoid, biceps, triceps, and quadriceps), and then progressively increased using a perceived exertion scale [with a target of 5-6 on a 10-point scale (35)]. All sessions were supervised by an experienced clinician, and the training intensity was increased during the training protocol.

Prospective follow-up of the COPD patients. We performed a prospective assessment of clinically relevant outcomes (all-cause mortality, hospital admissions, and acute exacerbations) up to March 1, 2013, in COPD patients. Acute exacerbations and admissions were 
obtained from the patients and verified with their medical doctors and respiratory practitioners. Survival status was obtained from direct interview of the patients or their relatives.

Statistical analysis. The explorative analysis was simplified using principal component analysis (PCA). Linear combinations of the variables formed new independent variables or components $(28,38)$. Components with eigenvalues $>1$ were kept. Results were visualized through a graph or map, in which the original variables or individuals are displayed, allowing easy visual interpretation of their relationships (9). Then, a cluster analysis based on the significant components of the PCA analysis was performed in individuals. Cluster analysis was performed using Ward's method. Next, the variables of the clusters of COPD patients and SHS were compared using one-way analysis of variance (12) or the Kruskall-Wallis test. Least significant differences were assessed with post hoc analysis (Bonferroni or Dunn). The level of significance was established at $P<0.05$. Statistical analysis was performed using the $\mathrm{R}$ statistical package, version 2.7.0.

\section{RESULTS}

Principal component analysis. The characteristics of the participants are presented in Table 1. PCA analysis was performed on 28 clinical and functional variables and muscle characteristics in 64 COPD patients and 27 SHS (Table 2). The four principal components significantly explained $61 \%$ of the information of the dataset. Figure 1 shows the projection of the variables on components 1 and 2 . We observed contributions of $\mathrm{FEV}_{1}$, the exercise capacity parameters (6-min walking distance, $\mathrm{VO}_{2} \mathrm{sl}$, etc.), quadriceps T.lim, and the type I fiber proportion on the $x$-axis (high modules along component 1). Component 2 was defined by fat-free and muscle mass, qMVC, fiber CSA, and sex. Last, the thoracopulmonary hyperinflation parameters and breathlessness contributed to components 1 and 3 (Table 2). In summary, exploratory visual analysis revealed three subgroups of redundant variables: the first was characterized by a reduced proportion of type I fibers, the second by muscle and fiber atrophy, and the last by pulmonary hyperinflation parameters.

Clustering analysis and classification of the subjects. The COPD patients and SHS were classified using the first two components. Then we used a hierarchical model of classification, which generated a dendrogram, and a grouping of the individuals. The optimal grouping was obtained with four clusters (Fig. 2). The characterization of the four clusters revealed very little overlap between COPD patients and SHS in all clusters. Clusters 3 and 4 included mostly SHS, while clusters 1 and 2 were exclusively composed of COPD patients (Table 3).

Regarding SHS, clusters 3 and 4 differed by sex: cluster 3 was exclusively female and, conversely, cluster 4 was nearly all male (13/1). The fiber CSA was significantly reduced in the females of cluster 3 compared with the males of cluster 4 . Regarding the COPD patients, cluster 1 was characterized by a significant reduction in the fiber CSA and a more severe reduction in the proportion of type I fibers. If the $F_{E V}$ (\%predicted) was lower in cluster 1 vs. cluster 2 COPD patients (30 [25-32] vs. 52 [44-70]; $P<0.001)$, there was no statistical difference between the age of the two clusters $(60.4 \pm 8.8$ vs. $60.8 \pm 9.0$ yr old; $P=0.87)$.

Table 1. Table of characteristics of the COPD patients and sedentary healthy subjects

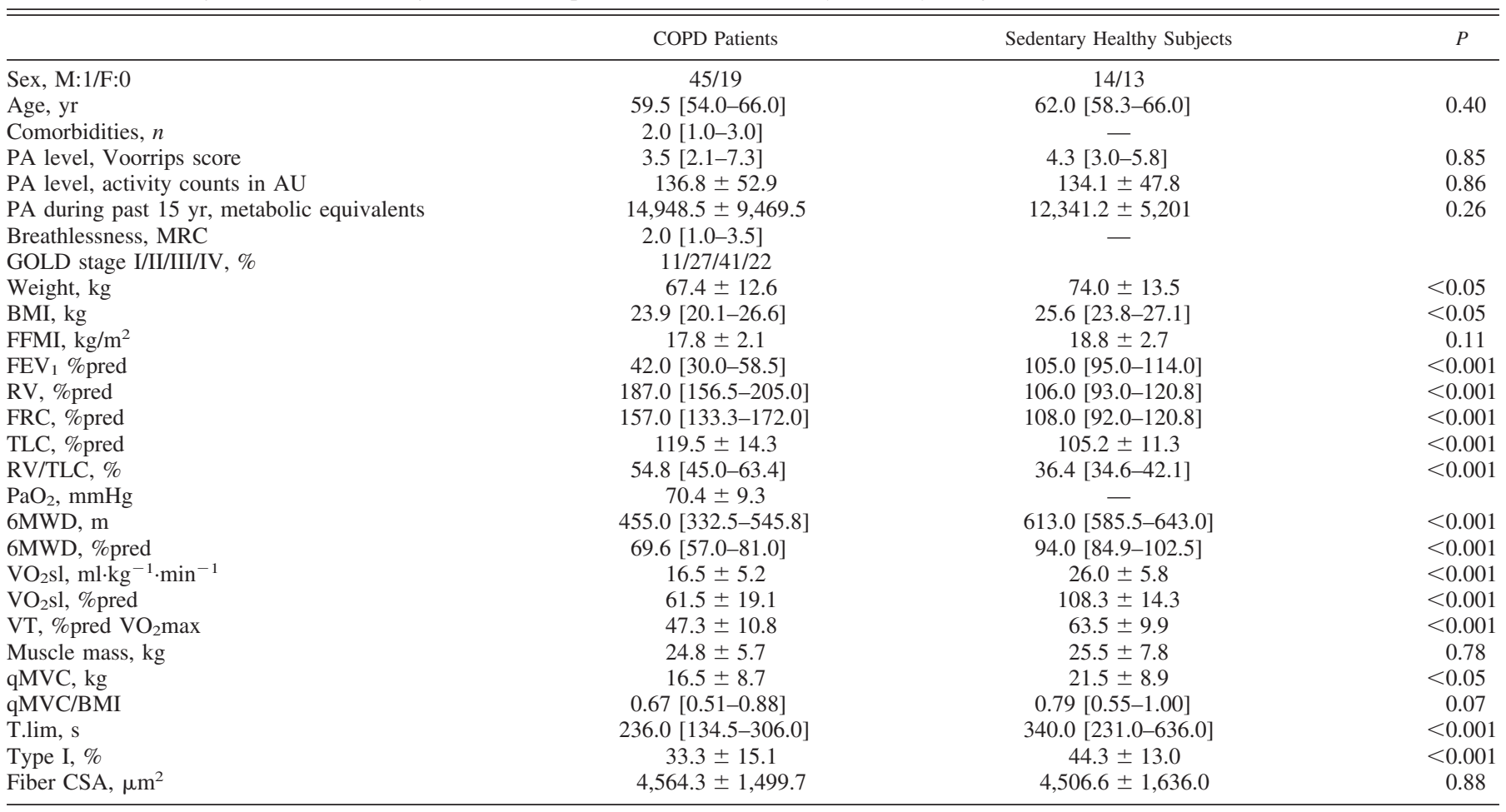

Results are expressed in means $\pm \mathrm{SD}$ or median [interquartile range (IQR)]. Definition of abbreviations: M, male; F, female; COPD, chronic obstructive pulmonary disease; SHS, sedentary healthy subjects; MRC, Medical Research Council; BMI, body mass index; \%pred, \% of the predicted value; FFMI, fat-free mass index; $\mathrm{FEV}_{1}$, forced expiratory volume in $1 \mathrm{~s} ; \mathrm{RV}$, residual volume; FRC, functional residual capacity; TLC, total lung capacity; $\mathrm{PaO} \mathrm{O}_{2}$, arterial oxygen partial pressure; $6 \mathrm{MWD}, 6$-minute walking distance; $\mathrm{VO}_{2} \mathrm{sl}$, symptom-limited oxygen uptake; VT, ventilatory threshold; $\mathrm{VO}_{2}$ max, maximum oxygen uptake; qMVC: quadriceps maximal voluntary contraction; T.lim, endurance time; fiber CSA, fiber cross-sectional area. 
Muscle Histomorphology and Phenotypes in COPD • Gouzi F et al.

Table 2. Correlations of the original variables with the four main components derived from the principal component analysis in the 91 subjects/COPD patients

\begin{tabular}{|c|c|c|c|c|}
\hline & Component 1 & Component 2 & Component 3 & Component 4 \\
\hline Disease status, COPD: $1 / \mathrm{SHS}: 0$ & 0.82 & 0.25 & -0.02 & -0.17 \\
\hline Age, yr & -0.01 & -0.13 & 0.45 & -0.40 \\
\hline Acute exacerbations, $n$ & 0.05 & 0.18 & 0.01 & -0.25 \\
\hline Breathlessness, MRC & 0.74 & -0.03 & 0.37 & 0.14 \\
\hline Weight, kg & -0.50 & 0.53 & 0.37 & -0.29 \\
\hline $\mathrm{FEV}_{1}, \%$ pred & -0.90 & -0.23 & -0.11 & -0.02 \\
\hline $\mathrm{RV}, \%$ pred & 0.72 & 0.37 & -0.48 & 0.03 \\
\hline FRC, \%pred & 0.69 & 0.33 & -0.52 & 0.00 \\
\hline TLC, \%pred & 0.38 & 0.23 & -0.62 & 0.00 \\
\hline VR/TLC, \% & 0.76 & 0.18 & -0.21 & -0.15 \\
\hline $\mathrm{PaO}_{2}, \mathrm{mmHg}$ & 0.01 & -0.16 & -0.29 & -0.03 \\
\hline $6 \mathrm{MWD}, \mathrm{m}$ & -0.73 & 0.13 & -0.47 & -0.29 \\
\hline Muscle mass, kg & -0.24 & 0.76 & 0.19 & 0.22 \\
\hline qMVC, kg & -0.47 & 0.69 & -0.21 & 0.18 \\
\hline gMVC/BMI & -0.36 & 0.64 & -0.34 & 0.32 \\
\hline T.lim, s & -0.33 & 0.07 & 0.14 & 0.06 \\
\hline Type I, \% & -0.48 & 0.10 & -0.28 & -0.38 \\
\hline Fiber CSA, $\mu \mathrm{m}^{2}$ & -0.26 & 0.70 & 0.03 & -0.23 \\
\hline
\end{tabular}

Correlations of the original variables with the three main components derived from the principal component analysis in the 91 individuals. The variance of components $1,2,3$ and 4 were $14.2,30.6,9.3$ and $6.5 \%$, respectively.

When comparisons were made with the SHS, taking into account the sex, reduction in the fiber CSA occurred only in male COPD patients in cluster 1 , and not in male COPD patients in cluster 2 , vs. the healthy males of cluster $4(3,715 \pm$ 1,316 vs. $5,657 \pm 1,098$ vs. $5,725 \pm 1,164 \mu \mathrm{m}^{2}$, respectively;

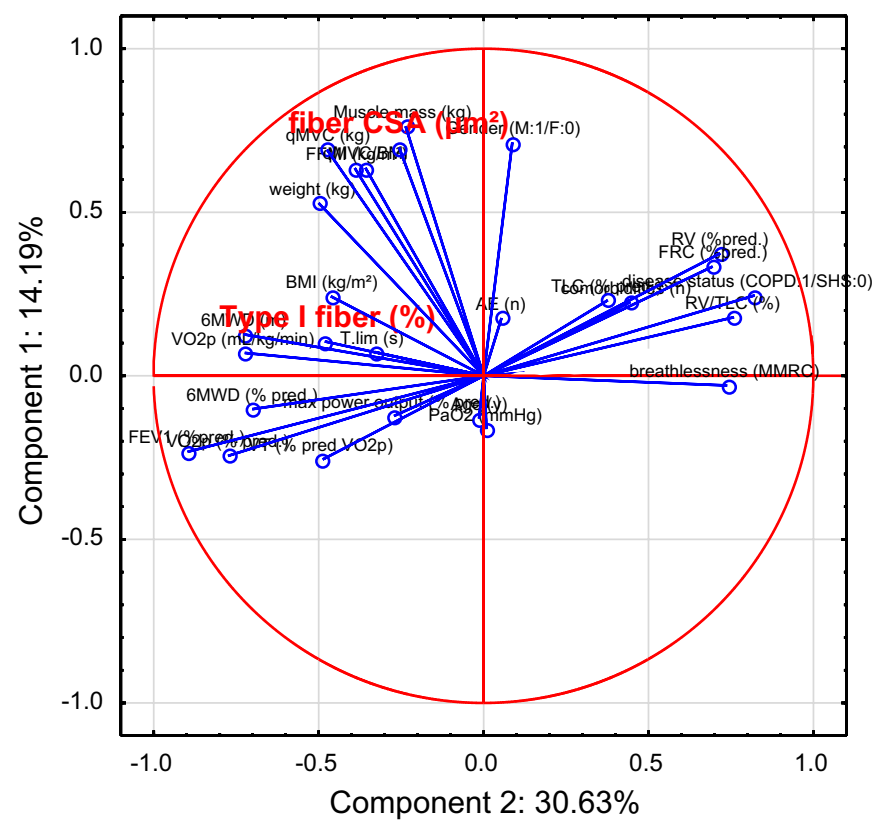

Fig. 1. Variable factor map obtained in all individuals $(n=91)$ by principal component analysis. The original variables are projected in a reduced dimension space defined by component 1 ( $x$-axis) and component 2 ( $y$-axis).
$P<0.05)$. In females, we found no significant difference in fiber CSA in clusters 1 and 2 vs. the healthy females of cluster 3. Nevertheless, compared with the SHS clusters, both COPD clusters showed significantly reduced type I fiber proportion $(P<0.05)$. In summary, the main muscle features in the clusters of COPD patients were a reduction in the type I fiber proportion with preserved fiber size for cluster 2 , and both fiber atrophy and severe type I fiber loss in cluster 1.

Validation of the phenotypes of COPD patients. Exercise training was performed at the intensity of the ventilatory $(n=$ $27 / 34)$ or dyspnea $(n=7 / 34)$ threshold in COPD patients only $(n=34 / 64)$. After training, we observed a significant improvement of the 6MWD $(n=34)$ and $\mathrm{VO} 2_{\mathrm{sl}}(n=19)$ in patients $\left(45 \pm 47 \mathrm{~m} ; P<0.001\right.$ and $+1.5 \pm 2.5 \mathrm{ml} \cdot \mathrm{kg}^{-1} \cdot \mathrm{min}^{-1} ; P<$ 0.05 , respectively). If we did not observe a significant greater relative improvement of the 6MWD in cluster 1 vs. cluster 2 $(+15.2 \pm 28.2 \%$ vs. $+6.5 \pm 6.3 \% ; P=0.21)$, there was a greater relative improvement of the $\mathrm{VO} 2_{\mathrm{sl}}$ after training in cluster 1 vs. cluster $2(+24 \pm 16 \%$ vs. $+6 \pm 13 \% ; P<0.01)$. The relative improvement of the $\mathrm{VO} 2_{\mathrm{sl}}$ was significantly correlated with the pretraining $\mathrm{VO}_{\mathrm{sl}}(r=-0.53 ; P<0.05, n=$ 19, Fig. 3). If the improvement of $\mathrm{VO} 2_{\mathrm{sl}}$ was higher in cluster 1 vs. cluster 2 , the training intensity (in $\%$ of the predicted $\left.\max \mathrm{VO}_{2}\right)$ was even lower in cluster 1 vs. cluster $2(40 \pm 4.6 \%$ vs. $49.9 \pm 10.7 \% ; P<0.05$ ).

The mean length of the follow-up in COPD patients was $1,040 \pm 418$ days $(n=54 / 64)$. At 1,500 days of follow-up, the higher all-cause mortality in cluster 1 vs. cluster 2 was not significant (log-rank: $1.15 ; P=0.26$ ). Kaplan-Meier analysis of hospital admissions and exacerbations between the 2 clus- 
Fig. 2. Factor map obtained in all individuals $(n=$ 91) by principal component analysis. Individuals are projected in a reduced dimension space defined by component 1 ( $x$-axis) and component 2 ( $y$-axis). Each color corresponds to a specific cluster.

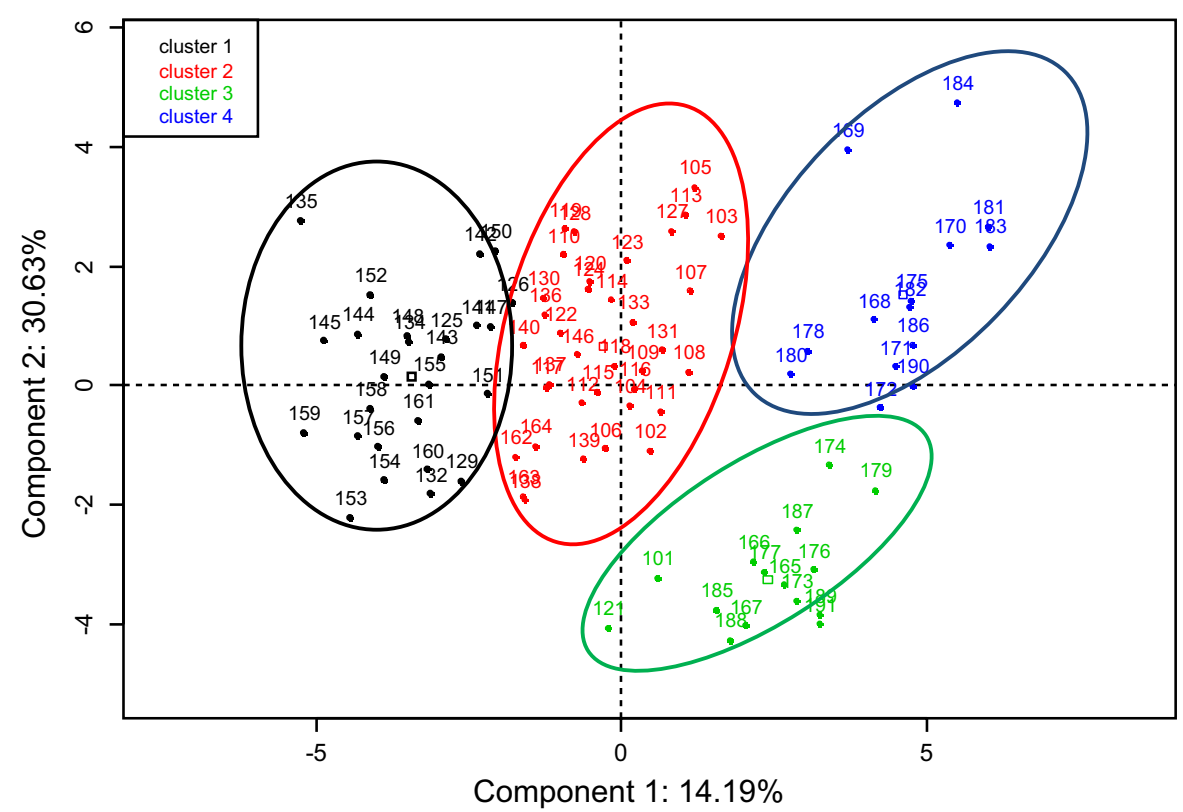

ters are presented in Fig. 4 and show that cluster 1 COPD patients were at higher risk of hospital admissions and exacerbations than cluster 2 (log-rank: 7.4 and 13.0, respectively; $P<0.001$ ). After adjustment for $\mathrm{FEV}_{1}$, the observed difference for hospital admission (hazard ratio: $1.41 ; P=0.50$ ) and exacerbations (hazard ratio: $2.43 ; P=0.11$ ) did not reach statistical significance.

Oxidative stress in clusters. We observed a significant increase in plasma isoprostane in cluster 1 of COPD patients $(P<0.05)$ compared with the others (Table 4). Given the differences regarding the plasma and muscle oxidative stress between males and females, comparisons between clusters were performed per sex. In males only, we observed a significant increase in the protein carbonylation $(/ \mathrm{IC} \%)$ of COPD patients in cluster 1 compared with patients in cluster 2 and SHS in cluster 4 (197.5 [106.3-214.9] vs. 80.8 [65.2-98.9] and 87.1 [70.9-103.9]; $P<0.05)$. A similar increase in MHC oxidation (/IC\%) was found in cluster 1 (117.5 [98.2-171.0] vs. 53.1 [30.3-124.5] and 62.5 [43.1-94.8]; $P<0.05$ ). Cluster comparisons in females revealed no significant difference for any marker of oxidative stress. The level of total muscle protein carbonylation and MHC oxidation was correlated with qMVC in the clusters of COPD patients $(r=-0.60 ; P<0.01$ and $r=-0.54 ; P<0.01 ;$ Fig. $5 A)$. Moreover, total protein and MHC carbonylation were inversely correlated with fiber CSA in COPD patients $(r=-0.64 ; P<0.001$ and $r=-0.67 ; P<$ 0.05 ; Fig. $5 B)$, as was catalase expression level $(r=-0.45$; $P<0.05)$.

\section{DISCUSSION}

Using unsupervised cluster analysis, we identified and validated two phenotypes of COPD patients (with different outcomes and response to exercise training) showing a different peripheral muscle histomorphology and level of oxidative stress. While cluster 1 "atrophic" COPD patients showed reduced BMI,

Table 3. Clinical, functional, and muscle characteristics in clusters of subjects/patients

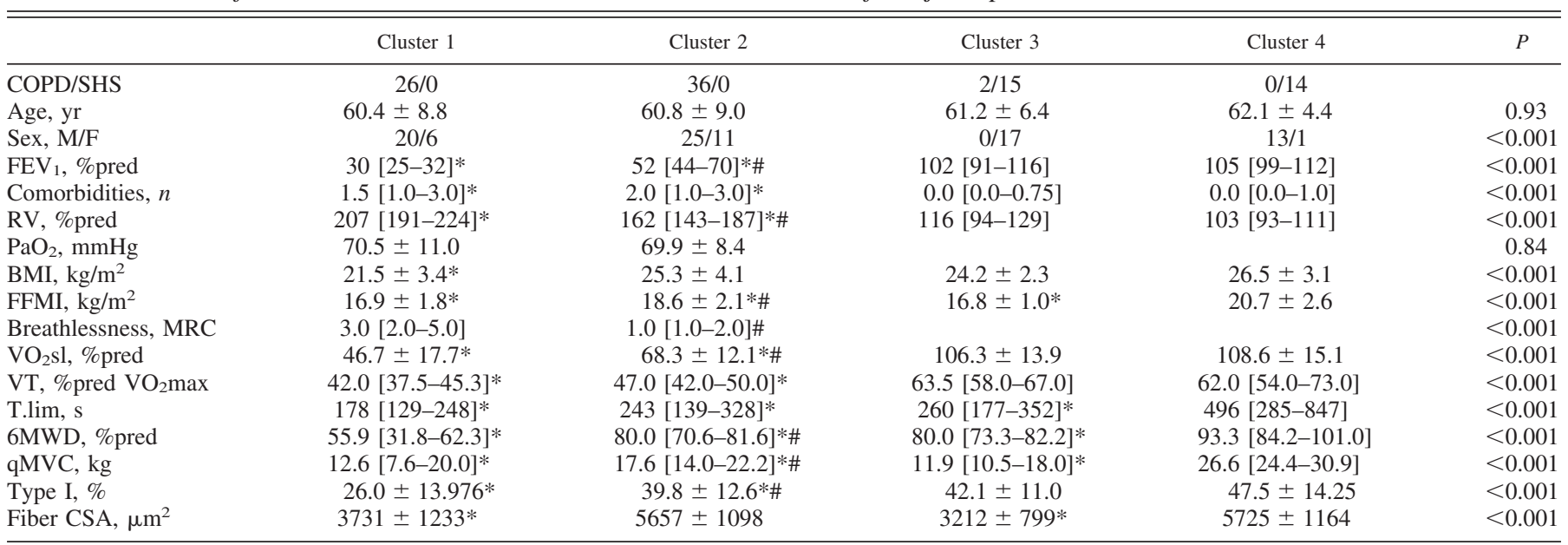

Results are expressed in means $\pm \mathrm{SD}$ or median [interquartile range (IQR)]. $* P<0.05$ vs. cluster 4 . \#P<0.05 vs. cluster 1 . 
A

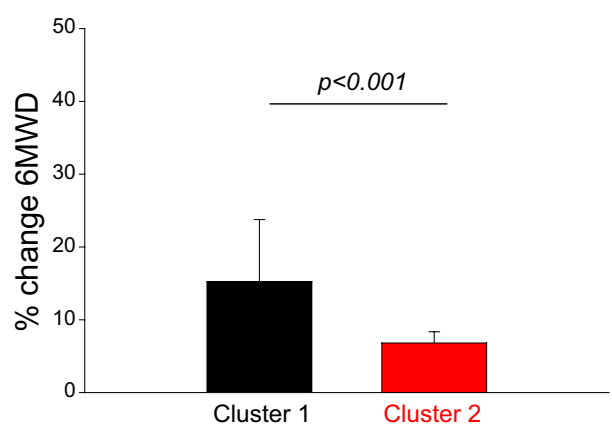

B

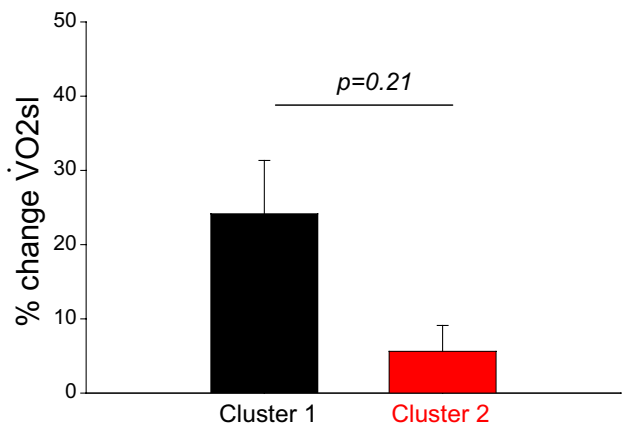

Fig. 3. Relative improvements of 6 minutes walking distance (6MWD) $(A)$ and symptomlimited oxygen uptake $\left(\mathrm{VO}_{\mathrm{si}}\right)(B)$ in cluster 1 (26) and cluster 2 (red) COPD patients, after a similar exercise training performed in a pulmonary rehabilitation course. Relative improvements of symptom-limited oxygen uptake $\left(\mathrm{VO} 2_{\text {sl }}\right)$, was inversely correlated with the baseline $\mathrm{VO}_{\mathrm{sl}}(\mathrm{r}=-0.53 ; \mathrm{p}=0.02)$ in 19 COPD patients (cluster 1: black, cluster 2: red) $(C)$.
FFMI, fiber CSA, and increased oxidative stress, cluster 2 COPD patients showed a moderate fiber switch. Thus our study robustly demonstrates that the muscle heterogeneity is the translation of different phenotypes of the disease.

Clusters of COPD patients correspond to different disease's phenotypes. If COPD patients with a reduction in their type I fiber proportion and without fiber atrophy have previously shown different attributes in previous studies $(9,10,18,34$, 54 ), it cannot be considered as a proof of different disease's phenotype. Indeed, a COPD phenotype is "a single or combination of disease attributes that describe differences between individuals with COPD as they relate to clinically meaningful outcomes [...]. The ultimate goal of phenotyping in medicine is to allow the identification of patient groups with unique prog- nostic or therapeutic characteristics" (24). Our clusters of COPD patients match this definition, because they showed a different response to a therapeutic intervention (i.e., exercise training): cluster 1 atrophic COPD showed a greater improvement of their relative $\mathrm{VO} 2_{\mathrm{sl}}$, which was significantly correlated with their baseline $\mathrm{VO} 2_{\mathrm{sl}}$. A similar result can be found in a recent study: the cachectic COPD patients with a reduced FFMI (matching the FFMI of our cluster 1 COPD patients) showed a greater relative improvement in the mean 6MWD compared with their noncachectic counterparts (55).

In addition, our clusters of COPD patients showed a different occurrence of clinically relevant outcomes: cluster 1 of COPD patients had more frequent hospitalizations and exacerbations. However, if no significant difference was detected
A

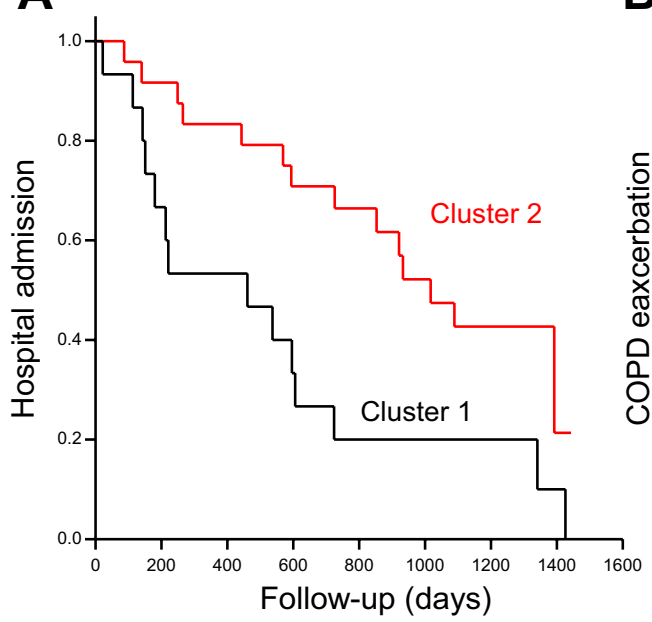

B

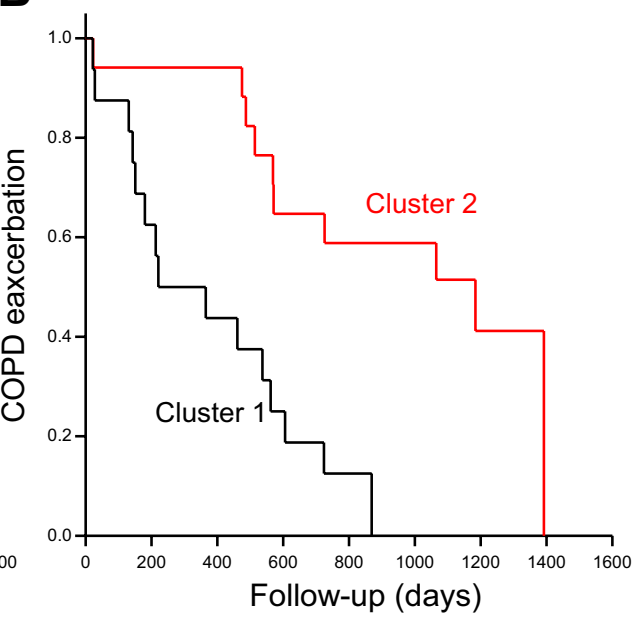

Fig. 4. Patterns of hospital admissions (A) and exacerbations $(B)$ during follow-up, according to the two chronic obstructive pulmonary disease (COPD) clusters identified by cluster analysis. 
Table 4. Oxidative stress markers in clusters of subjects/patients

\begin{tabular}{|c|c|c|c|c|c|}
\hline & Cluster 1 & Cluster 2 & Cluster 3 & Cluster 4 & $\mathrm{p}$ \\
\hline Muscle protein carbonylation & $131.5[83.6-200.3]$ & $83.0[68.3-105.1]$ & $103.7[88.5-111.5]$ & $91.8[74.3-126]$ & 0.12 \\
\hline Muscle oxidized MHC & $117.5[98.2-171.0]$ & $53.2[30.3-124.5]$ & $51.3[31.3-120.3]$ & $54.5[42.2-89.7]$ & 0.07 \\
\hline MnSOD,/GAPDH & $2.10 \pm 0.84$ & $1.76 \pm 0.97$ & $1.67 \pm 0.74$ & $1.47 \pm 0.51$ & 0.455 \\
\hline Glutathione reductase,/GAPDH & $0.78 \pm 0.49$ & $0.96 \pm 0.36$ & $0.93 \pm 0.34$ & $0.92 \pm 0.22$ & 0.814 \\
\hline Catalase,/GAPDH & $59.9 \pm 27.9$ & $35.5 \pm 17.1$ & $43.9 \pm 32.1$ & $45.4 \pm 34.9$ & 0.188 \\
\hline
\end{tabular}

Results are expressed in median [IQR]. MHC, myosin heavy chains; MnSOD, manganese superoxide dismutase; GAPDH, glyceraldehyde-3-phosphate dehydrogenase. ${ }^{*} P<0.05$ in post hoc analysis.

after adjustment for $\mathrm{FEV}_{1}$ in the occurrence of exacerbations and hospital admissions because of a small sample size $(n=$ 54), the observed $\mathrm{FEV}_{1}$-adjusted hazard ratio for exacerbations is in agreement with the higher frequency of exacerbations in COPD patients with reduced muscle mass or strength (11). In addition, a higher risk of hospital admission in the phenotype COPD patients with the lowest FFMI has already been observed, independently of the $\mathrm{FEV}_{1}$ (18). More generally, in terms of BMI, FFMI, and/or muscle weakness, our cluster 1 of COPD patients match a "cachectic" COPD population already


Fig. 5. Total protein carbonylation levels correlations with muscle strength and fiber cross-sectional areas (CSA). Total protein carbonylation levels, expressed as percentage of the internal control, were inversely correlated with the quadriceps maximal voluntary contraction $(r=-0.60 ; P<0.01)$ in all COPD patients (cluster 1: black, cluster 2: red) $(A)$; and total protein carbonylation levels, expressed as percentage of the internal control, were inversely correlated with the fiber cross-sectional area of the quadriceps $(r=-0.64, P<$ 0.001 ) in all COPD patients (cluster 1: black, cluster 2: red) $(B)$. isolated in five previous studies $(9,10,18,54,55)$, and prospectively validated in one of them (18).

A last observation argues for a difference of phenotypes, and not for a simple difference in the disease severity between groups. It was striking to note that the "cachectic" patients in cluster 1 (with body and fat-free mass loss) were not older than those in cluster $2(60.4 \pm 8.8$ vs. $60.8 \pm 9.0 \mathrm{yr} ; P=0.87)$. Another study also showed that the most cachectic phenotype was the youngest (9). In a larger population of COPD patients $(n=121)$ recruited at the same time and place and on the basis of the same inclusion criteria as the COPD patients of the present study, we found no significant difference for the age at breathlessness onset or the age of diagnosis, between clusters 1 and 2 (47.5 \pm 14.1 vs. $47.3 \pm 13.6 \mathrm{yr}, P=0.97$; and $54.3 \pm$ 11.3 vs. $52.3 \pm 11.8 \mathrm{yr}, P=0.48$ ). Then, assuming a similar age of disease onset, the disease course must have been more rapid in the "cachectic" patients of cluster 1 than in cluster 2 . This hypothesis has been confirmed by the longitudinal study of $\mathrm{FEV}_{1}$ decline in COPD patients: the "rapid decliner" phenotype was the most cachectic, like our cluster 1 (37). Moreover, a longitudinal study of qMVC and FFMI also showed faster decline in the patients with the lowest muscle mass (27). Last, oxidative stress has been shown to alter the decline in $\mathrm{FEV}_{1}$ (29). Therefore, the course of the disease in the cluster 1 cachectic patients with increased levels of oxidative stress (plasma isoprostan) must have been much more rapid. Altogether, with a specific time course, cluster 1 cannot be considered as the successive step from cluster 2 in the disease's time course, but rather as a specific COPD phenotype.

COPD patient clusters: different mechanisms in muscle? In our study, the COPD patients in cluster 1 showed fiber atrophy which was not observed in cluster 2 patients. We identified an increase in markers of plasma and muscle oxidative stress (protein oxidation) only in cluster 1 . This specific increase in the atrophic fibers of cluster 1 COPD patients may indicate a specific mechanism leading to the fiber atrophy in cluster 1 COPD patients, adding more evidence that cluster 1 COPD constitutes a real COPD phenotype. Indeed, it is currently admitted that oxidative stress has deleterious effects on muscle/ fiber mass in $\operatorname{COPD}(6,7,17,40)$. In addition, in vitro studies have shown that increased protein oxidation directly results in the activation of the calpain-dependent proteolysis pathway $(40,47,48)$ and the acceleration of myofibrillar degradation. An increased level of oxidative stress and activation of this pathway have been incriminated in various atrophy-related conditions $(6,48,49)$, and the significant correlations between total protein and MHC carbonylation and fiber CSA observed in our study support that this mechanism has occurred in the 
skeletal muscle of our COPD patients. Therefore, although we provide simple correlations and not a cause-effect relationship, cluster 1 COPD patients with fiber atrophy may have experienced a specific mechanism of accelerated oxidative stressinduced myofibrillar proteolysis (40). As "Phenotypes should exhibit [...] a similar underlying biologic or physiologic mechanism" (24), our results regarding oxidative stress markers argue also in favor of a phenotype grouping. Last, this observation appears relevant for the design of future studies exploring the mechanisms of the muscle atrophy in COPD. Indeed, our study showed that the combination of a poor lung function, a low exercise capacity, and a reduction of muscle mass or strength, rather than the use of a single parameter $(4,55)$, accurately isolated patients in which the specific processes leading to fiber atrophy are likely to occur.

Study critique. Our study was not designed to isolate all the potential phenotypes in COPD, because our aim was rather to test whether the fiber atrophy and type I fiber switch were the attributes of different phenotypes. Accordingly, the sampling size of our cluster analysis appears adequate (41) and consistent with previous published studies [number of subjects to the number of variables $=3.27$ vs. $2.28(18)]$. However, the question of potential unidentified phenotypes can be addressed. Indeed, in contrast with our observations and the study of Garcia-Aymerich et al. (18), two COPD phenotypes with evidence of muscle atrophy (high prevalence of muscle weakness) have been isolated in the study of Burgel et al. (10). Nonetheless, increasing the sample size could have allowed the isolation of an additional phenotype. Yet, regarding the similar level of muscle weakness (indicating similar degree of muscle atrophy) in phenotypes 2 and 3 in the study of Burgel et al. (10), it is probable that other COPD phenotypes would have a similar muscle structure.

A second limitation is the missing data, in particular for the PA level assessment. If most of the healthy subject had objective accelerometry recordings (22/27), 25 of the 64 COPD patients had this objective assessment. However, several precautions have been taken in order to include sedentary healthy controls (accelerometry, Voorrips score, clinical interview, QUANTAP system), and in COPD patients, the VMU and Voorrips score were equally distributed between cluster 1 and cluster 2 of COPD patients (VMU, $n=12$ vs. $n=13$; and Voorrips score, $n=15$ vs. $n=17$ ).

In conclusion, we identified and validated two phenotypes of COPD patients differing in terms of muscle dysfunction and histomorphology, with a specific occurrence of fiber atrophy in one of them. Thus our study demonstrates that the muscle heterogeneity is the translation of different phenotypes of the disease. The increased level of muscle oxidative stress in the phenotype with fiber atrophy suggests a specific pathobiological mechanism. The definition of these phenotypes may improve the identification of COPD patients requiring specific muscle interventions, as well as the identification of the cellular pathways involved in the muscle remodeling.

\section{ACKNOWLEDGMENTS}

We gratefully acknowledge A. Bourret and G. Hugon for technical support in the laboratory, all the team of "La Solane" and "La Vallonie" Pulmonary Rehabilitation Centers for their contribution to this work, and C. Stott, P. Pomiès, J. Maury and F. Bughin for critical reading of the manuscript. G. Caris and A. Suc are acknowledged for help with muscle biopsies.

\section{GRANTS}

This study was supported by joint grants from the CHRU Montpellier and the patient associations, APARD. Fr. Gouzi and A. Abdellaoui were supported by a "CIFRE grant" (Conventions Industrielles de Formation par la Recherche) from the Fontalvie Corporation, Toulouges, France, and the French "Ministère délégué à la recherche et aux nouvelles technologies".

\section{DISCLOSURES}

No conflicts of interest, financial or otherwise, are declared by the author(s).

\section{AUTHOR CONTRIBUTIONS}

Author contributions: F.G., J.M., M.H., and C.-G.P. conception and design of research; F.G., A.A., E.P., B.A., D.L.-C., J.-P.C., and M.H. performed experiments; F.G., A.A., N.M., E.P., B.A., D.L.-C., J.-P.C., M.H., and C.-G.P. analyzed data; F.G., A.A., N.M., E.P., B.A., D.L.-C., J.-P.C., J.M., M.H., and C.-G.P. interpreted results of experiments; F.G. and N.M. prepared figures; F.G. drafted manuscript; F.G., A.A., N.M., J.M., M.H., and C.-G.P. edited and revised manuscript; F.G., A.A., N.M., E.P., B.A., D.L.-C., J.-P.C., J.M., M.H., and C.-G.P. approved final version of manuscript.

\section{REFERENCES}

1. ATS. ATS statement: guidelines for the six-minute walk test. Am J Respir Crit Care Med 166: 111-117, 2002.

2. ATS/ACCP. ATS/ACCCP statement on cardiopulmonary exercise testing. Am J Respir Crit Care Med 167: 211-277, 2003.

3. Abdellaoui A, Prefaut C, Gouzi F, Couillard A, Coisy-Quivy M, Hugon G, Molinari N, Lafontaine T, Jonquet O, Laoudj-Chenivesse D, Hayot M. Skeletal muscle effects of electrostimulation after COPD exacerbation: a pilot study. Eur Respir J 38: 781-788, 2011.

4. Agusti A, Morla M, Sauleda J, Saus C, Busquets X. NF-kappaB activation and iNOS upregulation in skeletal muscle of patients with COPD and low body weight. Thorax 59: 483-487, 2004.

5. Barreiro E, Gea J, Corominas JM, Hussain SN. Nitric oxide synthases and protein oxidation in the quadriceps femoris of patients with chronic obstructive pulmonary disease. Am J Respir Cell Mol Biol 29: 771-778, 2003.

6. Barreiro E, Hussain SN. Protein carbonylation in skeletal muscles: impact on function. Antioxid Redox Signal 12: 417-429, 2010.

7. Barreiro E, Sieck G. Muscle dysfunction in COPD. J Appl Physiol 114: 1220-1221, 2013.

8. Bestall JC, Paul EA, Garrod R, Garnham R, Jones PW, Wedzicha JA. Usefulness of the Medical Research Council (MRC) dyspnoea scale as a measure of disability in patients with chronic obstructive pulmonary disease. Thorax 54: 581-586, 1999.

9. Burgel PR, Paillasseur JL, Caillaud D, Tillie-Leblond I, Chanez P, Escamilla R, Court-Fortune I, Perez T, Carre P, Roche N. Clinical COPD phenotypes: a novel approach using principal component and cluster analyses. Eur Respir J 36: 531-539, 2010.

10. Burgel PR, Paillasseur JL, Peene B, Dusser D, Roche N, Coolen J, Troosters T, Decramer M, Janssens W. Two distinct chronic obstructive pulmonary disease (COPD) phenotypes are associated with high risk of mortality. PLoS One 7: e51048, 2012.

11. Burtin C, Decramer M, Gosselink R, Janssens W, Troosters T. Rehabilitation and acute exacerbations. Eur Respir J 38: 702-712, 2011.

12. Celli BR, Cote CG, Marin JM, Casanova C, Montes de Oca M, Mendez RA, Pinto Plata V, Cabral HJ. The body-mass index, airflow obstruction, dyspnea, and exercise capacity index in chronic obstructive pulmonary disease. N Engl J Med 350: 1005-1012, 2004.

13. Couillard A, Maltais F, Saey D, Debigare R, Michaud A, Koechlin C, LeBlanc P, Prefaut C. Exercise-induced quadriceps oxidative stress and peripheral muscle dysfunction in patients with chronic obstructive pulmonary disease. Am J Respir Crit Care Med 167: 1664-1669, 2003.

14. Couillard A, Prefaut C. From muscle disuse to myopathy in COPD: potential contribution of oxidative stress. Eur Respir J 26: 703-719, 2005.

15. Delample D, Durand F, Severac A, Belghith M, Mas E, Michel F, Cristol JP, Hayot M, Prefaut C. Implication of xanthine oxidase in muscle oxidative stress in COPD patients. Free Radic Res 42: 807-814, 2008. 
16. Eliason G, Abdel-Halim S, Arvidsson B, Kadi F, Piehl-Aulin K. Physical performance and muscular characteristics in different stages of COPD. Scand J Med Sci Sports 19: 865-870, 2009.

17. Fermoselle C, Rabinovich R, Ausin P, Puig-Vilanova E, Coronell C, Sanchez F, Roca J, Gea J, Barreiro E. Does oxidative stress modulate limb muscle atrophy in severe COPD patients? Eur Respir J 40: 851-862, 2012

18. Garcia-Aymerich J, Gomez FP, Benet M, Farrero E, Basagana X, Gayete A, Pare C, Freixa X, Ferrer J, Ferrer A, Roca J, Galdiz JB, Sauleda J, Monso E, Gea J, Barbera JA, Agusti A, Anto JM. Identification and prospective validation of clinically relevant chronic obstructive pulmonary disease (COPD) subtypes. Thorax 66: 430-437, 2011.

19. Gosker HR, Engelen MP, van Mameren H, van Dijk PJ, van der Vusse GJ, Wouters EF, Schols AM. Muscle fiber type IIX atrophy is involved in the loss of fat-free mass in chronic obstructive pulmonary disease. Am J Clin Nutr 76: 113-119, 2002.

20. Gosker HR, Zeegers MP, Wouters EF, Schols AM. Muscle fibre type shifting in the vastus lateralis of patients with COPD is associated with disease severity: a systematic review and meta-analysis. Thorax 62: 944-949, 2007.

21. Gouzi F, Maury J, Molinari N, Pomies P, Mercier J, Prefaut CG, Hayot M. Reference values for vastus lateralis fiber size and type in healthy subjects over 40 years old: a systematic review and meta-analysis. J Appl Physiol 115: 346-354, 2013.

22. Gouzi F, Prefaut C, Abdellaoui A, Roudier E, de Rigal P, Molinari N, Laoudj-Chenivesse D, Mercier J, Birot O, Hayot M. Blunted muscle angiogenic training-response in COPD patients versus sedentary controls. Eur Respir J 41: 806-814, 2013.

23. Gouzi F, Prefaut C, Abdellaoui A, Vuillemin A, Molinari N, Ninot G, Caris G, Hayot M. Evidence of an early physical activity reduction in chronic obstructive pulmonary disease patients. Arch Phys Med Rehabil 92: 1611-1617, 2011.

24. Han MK, Agusti A, Calverley PM, Celli BR, Criner G, Curtis JL, Fabbri LM, Goldin JG, Jones PW, Macnee W, Make BJ, Rabe KF, Rennard SI, Sciurba FC, Silverman EK, Vestbo J, Washko GR, Wouters EF, Martinez FJ. Chronic obstructive pulmonary disease phenotypes: the future of COPD. Am J Respir Crit Care Med 182: 598-604, 2010.

25. Hayot M, Michaud A, Koechlin C, Caron MA, Leblanc P, Prefaut C, Maltais F. Skeletal muscle microbiopsy: a validation study of a minimally invasive technique. Eur Respir J 25: 431-440, 2005.

26. Ho TK, Rajkumar V, Black CM, Abraham DJ, Baker DM. Increased angiogenic response but deficient arteriolization and abnormal microvessel ultrastructure in critical leg ischaemia. Br J Surg 93: 1368-1376, 2006

27. Hopkinson NS, Tennant RC, Dayer MJ, Swallow EB, Hansel TT, Moxham J, Polkey MI. A prospective study of decline in fat free mass and skeletal muscle strength in chronic obstructive pulmonary disease. Respir Res 8: 25, 2007.

28. Jolliffe I. Principal Component Analysis. New York: Springer, 2002, p. 90-101.

29. Keranis E, Makris D, Rodopoulou P, Martinou H, Papamakarios G, Daniil Z, Zintzaras E, Gourgoulianis KI. Impact of dietary shift to higher-antioxidant foods in COPD: a randomised trial. Eur Respir $J$ 36: 774-780, 2010.

30. Koechlin C, Maltais F, Saey D, Michaud A, LeBlanc P, Hayot M, Prefaut C. Hypoxaemia enhances peripheral muscle oxidative stress in chronic obstructive pulmonary disease. Thorax 60: 834-841, 2005.

31. Kyle UG, Genton L, Karsegard L, Slosman DO, Pichard C. Single prediction equation for bioelectrical impedance analysis in adults aged 20-94 years. Nutrition 17: 248-253, 2001

32. Marin-Corral J, Minguella J, Ramirez-Sarmiento AL, Hussain SN, Gea J, Barreiro E. Oxidised proteins and superoxide anion production in the diaphragm of severe COPD patients. Eur Respir J 33: 1309-1319, 2009.

33. Marquis K, Debigare R, Lacasse Y, LeBlanc P, Jobin J, Carrier G, Maltais F. Midthigh muscle cross-sectional area is a better predictor of mortality than body mass index in patients with chronic obstructive pulmonary disease. Am J Respir Crit Care Med 166: 809-813, 2002.

34. Natanek SA, Gosker HR, Slot IG, Marsh GS, Hopkinson NS, Man WD, Tal-Singer R, Moxham J, Kemp PR, Schols NM, Polkey MI. Heterogeneity of quadriceps muscle phenotype in chronic obstructive pulmonary disease (COPD); implications for stratified medicine? Muscle Nerve 2013.
35. Nelson ME, Rejeski WJ, Blair SN, Duncan PW, Judge JO, King AC, Macera CA, Castaneda-Sceppa C. Physical activity and public health in older adults: recommendation from the American College of Sports Medicine and the American Heart Association. Med Sci Sports Exerc 39: 1435-1445, 2007.

36. Nici L, Donner C, Wouters E, Zuwallack R, Ambrosino N, Bourbeau J, Carone M, Celli B, Engelen M, Fahy B, Garvey C, Goldstein R, Gosselink R, Lareau S, MacIntyre N, Maltais F, Morgan M, O'Donnell D, Prefault C, Reardon J, Rochester C, Schols A, Singh S, Troosters T. American Thoracic Society/European Respiratory Society statement on pulmonary rehabilitation. Am J Respir Crit Care Med 173: 1390-1413, 2006.

37. Nishimura M, Makita H, Nagai K, Konno S, Nasuhara Y, Hasegawa M, Shimizu K, Betsuyaku T, Ito YM, Fuke S, Igarashi T, Akiyama Y, Ogura S. Annual change in pulmonary function and clinical phenotype in chronic obstructive pulmonary disease. Am J Respir Crit Care Med 185: $44-52,2011$

38. Pifferi M, Bush A, Pioggia G, Caramella D, Tartarisco G, Di Cicco M, Zangani M, Chinellato I, Maggi F, Tezza G, Macchia P, Boner A. Evaluation of pulmonary disease using static lung volumes in primary ciliary dyskinesia. Thorax 67: 993-999, 2012.

39. Poulain M, Durand F, Palomba B, Ceugniet F, Desplan J, Varray A, Prefaut C. 6-minute walk testing is more sensitive than maximal incremental cycle testing for detecting oxygen desaturation in patients with COPD. Chest 123: 1401-1407, 2003.

40. Powers SK, Kavazis AN, McClung JM. Oxidative stress and disuse muscle atrophy. J Appl Physiol 102: 2389-2397, 2007.

41. Preacher KJ, MacCallum RC. Exploratory factor analysis in behavior genetics research: factor recovery with small sample sizes. Behav Genet 32: 153-161, 2002.

42. Préfaut C, Gautier-Dechaud V, Fuchs-Climent D, Poulain M. Quality of life in patients with chronic obstructive pulmonary disease on long-term oxygen therapy: role of exercise training. Human Kinetics 15: 177-186, 2000.

43. Qaseem A, Wilt TJ, Weinberger SE, Hanania NA, Criner G, van der Molen T, Marciniuk DD, Denberg T, Schunemann H, Wedzicha W, MacDonald R, Shekelle P. Diagnosis and management of stable chronic obstructive pulmonary disease: a clinical practice guideline update from the American College of Physicians, American College of Chest Physicians, American Thoracic Society, and European Respiratory Society. Ann Intern Med 155: 179-191, 2011.

44. Quanjer PH, Tammeling GJ, Cotes JE, Pedersen OF, Peslin R, Yernault JC. Lung volumes and forced ventilatory flows. Report Working Party Standardization of Lung Function Tests, European Community for Steel and Coal Official Statement of the European Respiratory Society. Eur Respir J Suppl 16: 5-40, 1993.

45. Remels AH, Gosker HR, Langen RC, Schols AM. The mechanisms of cachexia underlying muscle dysfunction in COPD. J Appl Physiol 114: 1253-1262, 2013.

46. Serres I, Varray A, Vallet G, Micallef JP, Prefaut C. Improved skeletal muscle performance after individualized exercise training in patients with chronic obstructive pulmonary disease. J Cardiopulm Rehabil 17: 232-238, 1997.

47. Seymour JM, Ward K, Sidhu PS, Puthucheary Z, Steier J, Jolley CJ, Rafferty G, Polkey MI, Moxham J. Ultrasound measurement of rectus femoris cross-sectional area and the relationship with quadriceps strength in COPD. Thorax 64: 418-423, 2009.

48. Smuder AJ, Kavazis AN, Hudson MB, Nelson WB, Powers SK. Oxidation enhances myofibrillar protein degradation via calpain and caspase-3. Free Radic Biol Med 49: 1152-1160, 2010.

49. Smuder AJ, Kavazis AN, Min K, Powers SK. Exercise protects against doxorubicin-induced oxidative stress and proteolysis in skeletal muscle. $J$ Appl Physiol 110: 935-942, 2011.

50. Steele BG, Holt L, Belza B, Ferris S, Lakshminaryan S, Buchner DM. Quantitating physical activity in COPD using a triaxial accelerometer. Chest 117: 1359-1367, 2000.

51. Swallow EB, Reyes D, Hopkinson NS, Man WD, Porcher R, Cetti EJ, Moore AJ, Moxham J, Polkey MI. Quadriceps strength predicts mortality in patients with moderate to severe chronic obstructive pulmonary disease. Thorax 62: 115-120, 2007.

52. Vallet G, Ahmaidi S, Serres I, Fabre C, Bourgouin D, Desplan J, Varray A, Prefaut C. Comparison of two training programmes in chronic airway limitation patients: standardized versus individualized protocols. Eur Respir J 10: 114-122, 1997.

53. van den Borst B, Slot IG, Hellwig VA, Vosse BA, Kelders MC, Barreiro E, Schols AM, Gosker HR. Loss of quadriceps muscle oxida- 
tive phenotype and decreased endurance in patients with mild-to-moderate COPD. J Appl Physiol 114: 1319-1328, 2013.

54. Vanfleteren LE, Spruit MA, Groenen M, Gaffron S, van Empel VP, Bruijnzeel PL, Rutten EP, Op 't Roodt J, Wouters EF, Franssen FM. Clusters of comorbidities based on validated objective measurements and systemic inflammation in patients with chronic obstructive pulmonary disease. Am J Respir Crit Care Med 187: 728-735, 2013.
55. Vogiatzis I, Simoes DC, Stratakos G, Kourepini E, Terzis G, Manta P, Athanasopoulos D, Roussos C, Wagner PD, Zakynthinos S. Effect of pulmonary rehabilitation on muscle remodelling in cachectic patients with COPD. Eur Respir J 36: 301-310, 2010.

56. Voorrips LE, Ravelli AC, Dongelmans PC, Deurenberg P, Van Staveren WA. A physical activity questionnaire for the elderly. Med Sci Sports Exerc 23: 974-979, 1991.



